Review Article

\title{
Assessing the Increase of Snakebite Incidence in Relationship to Flooding Events
}

\author{
Carlos Ochoa $\mathbb{D}^{1},{ }^{1,2}$ Isabelle Bolon $\mathbb{D}^{1},{ }^{1}$ Andrew M. Durso ${ }^{(D)},{ }^{1,3}$ Rafael Ruiz de Castañeda $(\mathbb{D}){ }^{1}$ \\ Gabriel Alcoba $\mathbb{D}^{1,4,5}$ Sara Babo Martins $\mathbb{D}^{1},{ }^{1}$ François Chappuis $\mathbb{D}^{1,},{ }^{1,4}$ and Nicolas Ray $\mathbb{D}^{1,2}$ \\ ${ }^{1}$ Institute of Global Health, Department of Community Health and Medicine, Faculty of Medicine, University of Geneva, \\ 1202 Geneva, Switzerland \\ ${ }^{2}$ Institute for Environmental Sciences, University of Geneva, 1205 Geneva, Switzerland \\ ${ }^{3}$ Department of Biological Sciences, Florida Gulf Coast University, Ft Myers, FL 33965, USA \\ ${ }^{4}$ Division of Tropical and Humanitarian Medicine, Geneva University Hospitals, 1206 Geneva, Switzerland \\ ${ }^{5}$ Médecins Sans Frontières-Doctors Without Borders, 1211 Geneva, Switzerland
}

Correspondence should be addressed to Carlos Ochoa; carlos.ochoa@unige.ch

Received 23 September 2019; Accepted 27 April 2020; Published 18 May 2020

Academic Editor: Amir Radfar

Copyright ( 2020 Carlos Ochoa et al. This is an open access article distributed under the Creative Commons Attribution License, which permits unrestricted use, distribution, and reproduction in any medium, provided the original work is properly cited.

\begin{abstract}
Snakebite envenoming causes up to 138,000 deaths and 400,000 permanently disabled victims worldwide every year. Flooding is one of the many factors that seems to influence the incidence of snakebite. The catastrophic floods from late 2018 in Kerala (India) were widely broadcast and are an example of how flooding events are related to the increased incidence of snakebite. This relationship has been mentioned regularly in scientific and grey literature, but usually quite scarcely in comparison to other topics linked to snakebite. Additionally, web media, mobile communications, and social media have started playing an important role not only in providing access to information on flooding-related snakebite events, but also in snakebite prevention at a larger scale. In order to better understand to what extent the relationship between snakebite incidence and flooding is reported and quantified and appraise the importance of mobile communications and social media in snakebite prevention and management, we performed multiple searches in generic (Google) and specialized (PubMed, Web of Science, Google Scholar) databases. We retrieved 68 scientific articles and 5 reports ranging from 1892 to 2018 mentioning or analyzing flooding and the increased incidence of snakebite. Additionally, we found 68 web media reports linking flooding and snakebite. This review indicates that the increase of snakebite incidence due to flooding has been repeatedly observed all over the world. This phenomenon could be exacerbated because of climate change, which is expected to increase the overall magnitude and frequency of flooding. However, it could also be mitigated by the role the Internet, mobile communications, and social media could play in snakebite prevention and human and animal rescue strategies during flooding.
\end{abstract}

\section{Introduction}

Snakebite envenoming is a greatly underreported neglected tropical disease (NTD) responsible for up to 138,000 deaths and 400,000 permanently disabled victims worldwide every year [1]. The link between flooding and increased snakebite incidence has been recurrently, but unremarkably mentioned in the scientific literature [1-47]. Formatively, the increase in snakebite cases after a flooding event in 1891 was what led French physician Albert Calmette to develop the first antivenoms [8]. In addition, within the recommendations addressed to the World Health Organization (WHO) to put snakebite back onto its official list of NTDs in 2017, flooding was given as one of the main environmental risk factors leading to an increased incidence of snakebite [48].

During late August and early September 2018, web media storm followed the devastating floods in the region of Kerala in India, the worst of such events since 1924 [49]. More than 20 different online news sources, from at least 10 countries and the WHO, covered the news. However, this time, the focus was not just on the destruction produced by the flooding itself, but also on the many snakes apparently 
left by the receding waters. This displacement of snakes, and the reported rise in snakebite incidence, caused additional distress and fear among the flood-affected population. As an answer to this threat, experts from the Wildlife Trust of India, the Indian Snakebite Initiative, and public relations office of the state government put in place a support strategy including WhatsApp numbers used to contact experts to identify, capture, and relocate snakes (see entries 1.20, 1.68, and 1.70 in Appendix S1 in the supplementary material. This continues a recent trend where mobile communications (text messages, WhatsApp, Twitter, etc. are becoming increasingly common in supporting humanitarian emergencies worldwide $[50,51]$.

In some of the world's snakebite hyperendemic areas, seasonal snakebite peaks are often linked to rainy seasons (Table 1), which in South Asia are directly associated with monsoons. Similarly, flooding due to hurricanes and cyclones has been connected to an increased incidence of snakebite in the United States [45], the Gulf of Yucatan in Mexico [46], and Odisha in India [33, 75]. An explanation for this correlation seems to lie with the natural tendency of all terrestrial animals to seek dry, higher grounds during flooding $[22,36,45,63,64]$. Snakes are likely to abandon flooded burrows or be swept from their home ranges $[2,6,16,26,37,65]$, ending up in or near human dwellings and other places where animals and humans seek refuge, bringing them into closer contact $[7,12,20,30]$.

Our objectives are

(1) To highlight what seems to be a natural response of snakes to flooding.

(2) To understand the extent to which increased snakebite is reported during floods.

(3) To gauge the importance of newly available communication resources in preventing the negative consequences of these encounters for humans and snakes.

\section{Methods}

We conducted a series of online searches using different databases to understand the extent of literature and media coverage of the events linking increased snakebite incidence to flooding. To get a wider overview of this phenomenon, we not only searched for scientific and grey literature, but also for web media, which is becoming increasingly important for sharing information, educating the public, and managing disasters.

For the scientific and grey literature, we carried out comprehensive searches between September 25 and November 30, 2018, in three specialized databases: PubMed, Web of Science, and Google Scholar (Appendix S1 in the supplementary material). We considered any publication that mentioned a relationship between snakebite incidence and flooding. In a few cases, we also included publications discussing the effects of flooding on snakes that could give contextual support. Additionally, we looked for further grey literature using cascade searches from references previously found and results from databases of international health organizations (i.e. the WHO and the Pan American Health
Organization). For the web media reports, we started by running a general search in Google for information about the latest Kerala floods (flood AND Kerala AND snake). We analyzed the first 120 entries (up to the point where sites or sources started to reappear), and we selected all mentioning the increase of snakebite cases or snakes occupying homes and shelters after the flood. Then, we expanded our evaluation by running an advanced Google search in four languages (English: snake flood snakebite OR snake-bite OR "snake bite" -piercing -filter needed to avoid hits about a type of body piercing called snakebite-; Spanish: inundación OR inundaciones AND "mordedura de serpiente"; French: inondation AND "morsure de serpent"; German: Überschwemmung AND Schlangenbisse) to include results from other countries (both target and source). From each source, whenever available, we gathered the following details: authors (or news provider), location, publication date, snake species reported, snakebite increase, climatic conditions, and the circumstances associated with the phenomenon (Figure 1).

We assumed "flooding" as the main term defining a climatological event presumably leading to increased incidence of snakebite because it was mentioned in almost all the reports found (either alone or with additional causes). However, depending on their scope, the wording used in some articles included "intense precipitation" (in experimental ecology) or simply "monsoon," assuming a tacit understanding of what this phenomenon implies for the South Asian region (in clinical epidemiology).

It is important to clarify that not all snake bites lead to envenomation. This is because they are either "dry bites" or they are from nonvenomous snakes [1]. Here, it was not possible to stratify our findings by the risks posed by each type of bite, as too little information was available. However, despite a reasonable assumption that flooding would affect most species of snakes and therefore their proximity to humans and probability of bites similarly, it is also probable that the underreporting affecting venomous snakebite is even greater for non-venomous cases.

\section{Results}

The specific searches for scientific and grey literature generated 68 articles and 5 reports, respectively. Grouped results summarizing the number of reports found by country and type of publication are presented in Figure 2 and detailed in Table S2 in the supplementary material. We found 25 online news sources about the events in Kerala. Using Google's advanced search, we found 43 additional web media reports connecting increased incidence of snakebite with flooding ( entries 1.1-1.68 in Appendix S1 in the supplementary material).

In addition to "flooding," in the scientific literature, several authors gave other reasons to explain the acknowledged increase of snakebite incidence (Table 1). These reasons are connected either to the causes of flooding or to the environmental and ecological consequences of it. Web media, in much shorter reports, also gave "flooding" as the main cause for increased incidence of snakebite 
TABLE 1: Flooding and other associated reasons for increased incidence of snakebite in scientific literature. The percentages of appearance do not add up to $100 \%$, since several causes are mentioned per report.

\begin{tabular}{|c|c|c|c|}
\hline Topic & Details & References & $\%$ \\
\hline Flooding & $\begin{array}{l}\text { Increased snakebite } \\
\text { incidence during } \\
\text { flooding events }\end{array}$ & {$[1-48,52-62]$} & 86.8 \\
\hline Habitat & $\begin{array}{l}\text { Flooded burrows and } \\
\text { habitats force snakes } \\
\text { to find shelter in } \\
\text { higher grounds }\end{array}$ & {$[2,6,7,12,13,16-22,24,26,27,30,36,37,40,41,44,45,52,54,56,58,60,63-66]$} & 45.6 \\
\hline $\begin{array}{l}\text { Seasonal } \\
\text { peak }\end{array}$ & $\begin{array}{l}\text { Snakebite peaks are } \\
\text { linked to the rainy } \\
\text { season(s) }\end{array}$ & {$[1,3,5-7,9-15,17,20,23,27-30,32,35-37,40,43,44,47,55-59,61,64,66-68]$} & 54.4 \\
\hline Agriculture & $\begin{array}{l}\text { Agricultural activities } \\
\text { increase exposure and } \\
\text { take place during the } \\
\text { rainy season }\end{array}$ & {$[1-4,6,9-13,15,17,20,23,27,29,35-37,39,43,44,47,52,55,56,60,61,66,68-74]$} & 52.9 \\
\hline $\begin{array}{l}\text { Snake's } \\
\text { prey }\end{array}$ & $\begin{array}{l}\text { The number of several } \\
\text { prey species grows } \\
\text { during the rainy } \\
\text { season (or are also } \\
\text { displaced) }\end{array}$ & {$[9,18-20,24,29,30,39,41,43,44,52,56,70]$} & 20.6 \\
\hline Monsoon & $\begin{array}{l}\text { Snakebite peaks are } \\
\text { usually linked to the } \\
\text { monsoon in Asia }\end{array}$ & {$[2-4,6,9,12,13,16,18,19,21,24-26,29,30,32,34,36,39,41-44,52-54,56,58,60,62]$} & 45.6 \\
\hline
\end{tabular}

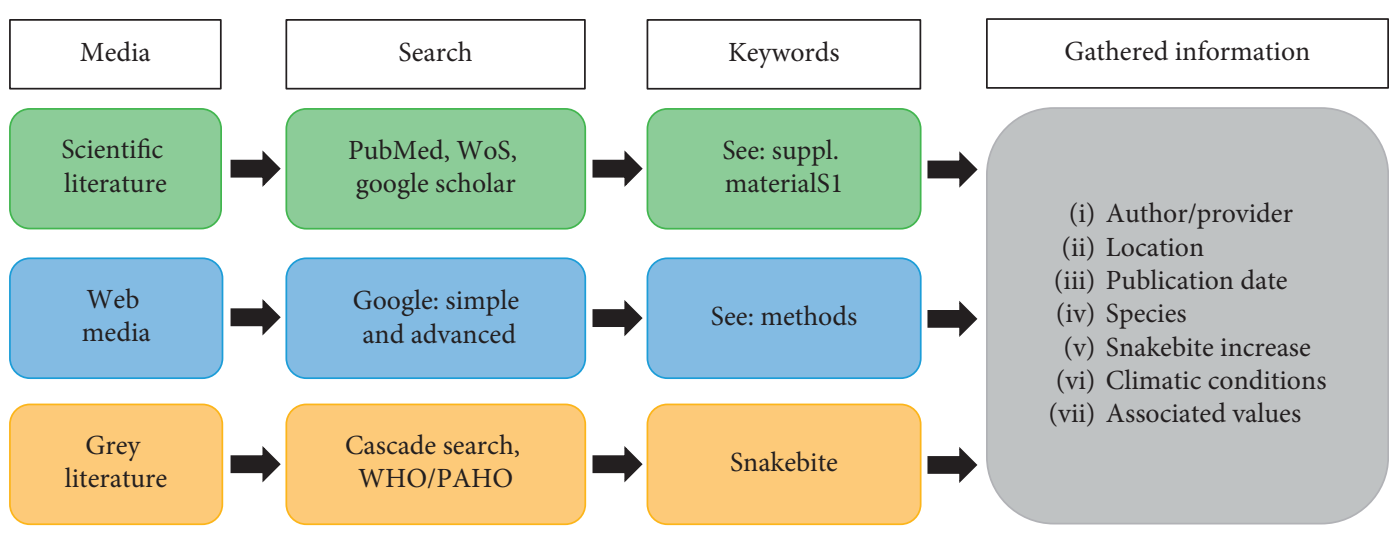

FIgURE 1: Workflow of the literature review process.

(70.8\% of the reports), followed by the argument that flooded burrows force snakes to search dry, higher grounds (20.8\%).

Of the scientific publications focusing on Asian countries, $61.5 \%$ indicated a relationship between "the monsoon" and the increase of snakebite. In South America, intense rains caused by the El Niño-Southern Oscillation have also been linked to more snakebite cases in Ecuador [17]. Similarly, between 2015 and 2018, several United States news sources identified torrential rain, from hurricanes such as Irma (early September 2017) and Florence (early September 2018), as a cause of more snakebite cases in the southern states of Texas, Oklahoma, Alabama, North and South Carolina, Missouri, and Florida (Appendix S1 in the supplementary material).
While $92.3 \%$ of the articles positively associated flooding with increased snakebite, a few exceptions (7.7\%) did not detect or report any incidence increase or reported that the rainy season and the associated flooding were negatively correlated with snakebite incidence $[22,60,63,70,77]$. We did not find any studies focusing on and analyzing the actual effects of flooding and similar catastrophic climatic events on snakebite incidence. Within the articles quantifying the association between flooding (or related weather patterns) and snakebite incidence, the large majority $(83.8 \%)$ were retrospective clinical or epidemiological studies $[4,6,7,9,12,13,18-20,23-26,28-30,34,35,37,40$, $41,43,60,66,77,78]$. Most of them (25) provided comparable summary statistics that along with two surveys [27, 44] and one paper on economic burden [39] allowed us to analyze their results for the monthly number of snakebite cases according to 


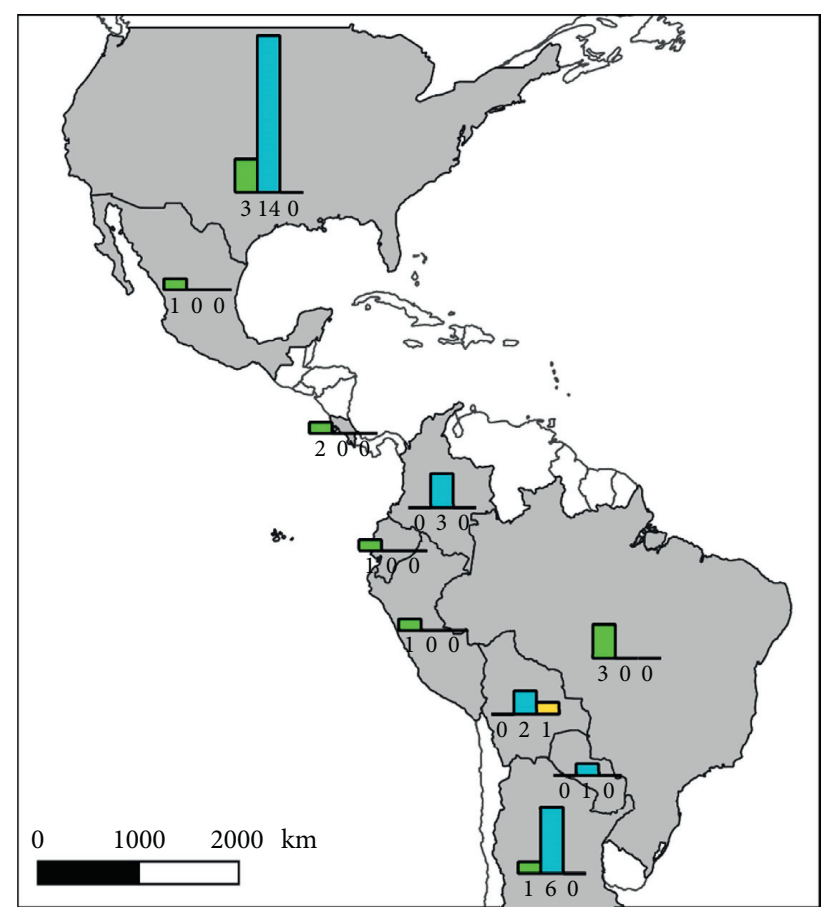

Reported countries

Scientific literature

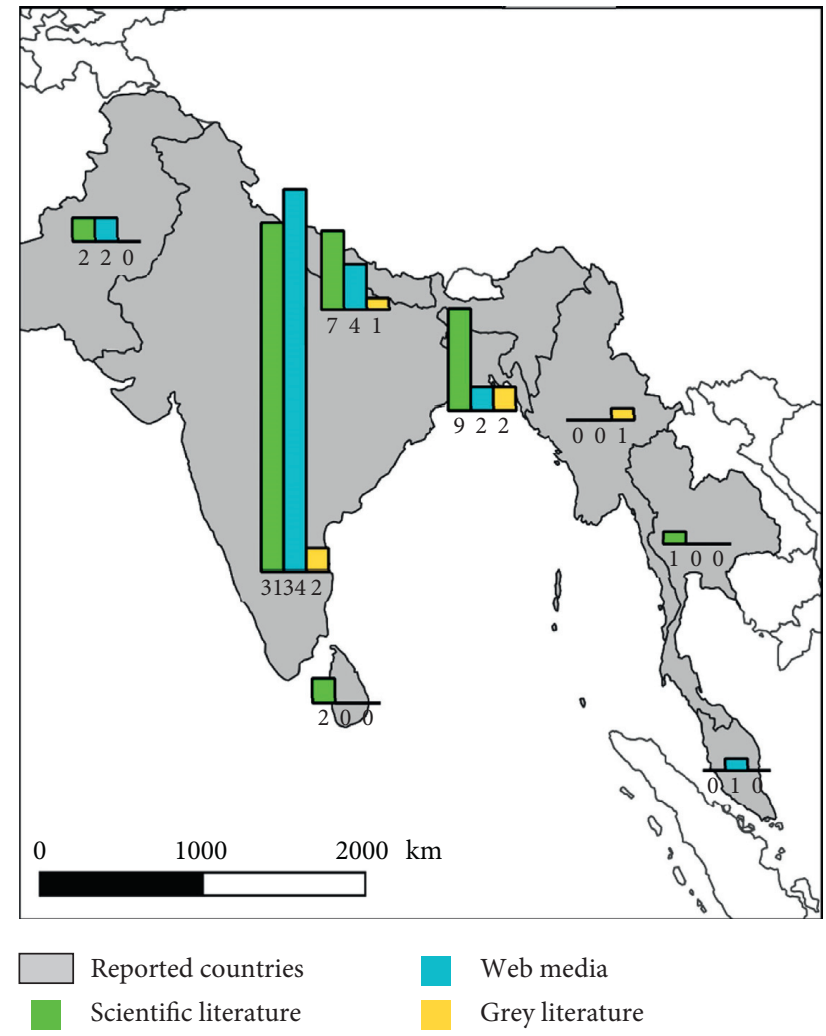

Reported countries

Scientific literature

Web media

Grey literature

(a)

(c)

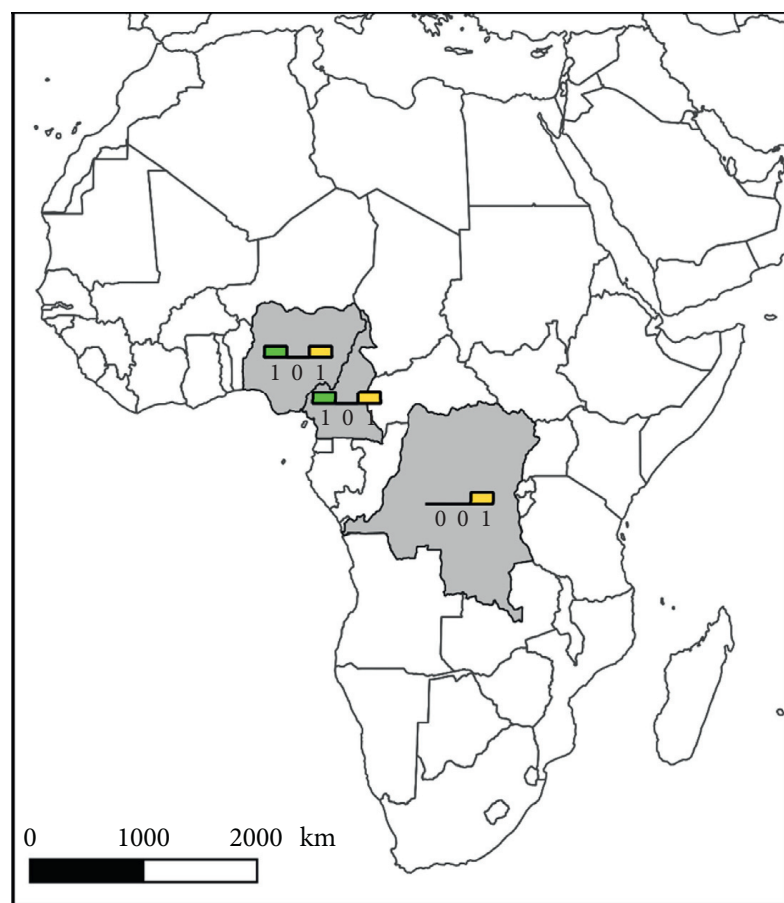

Reported countries

Web media

Scientific literature

(b)

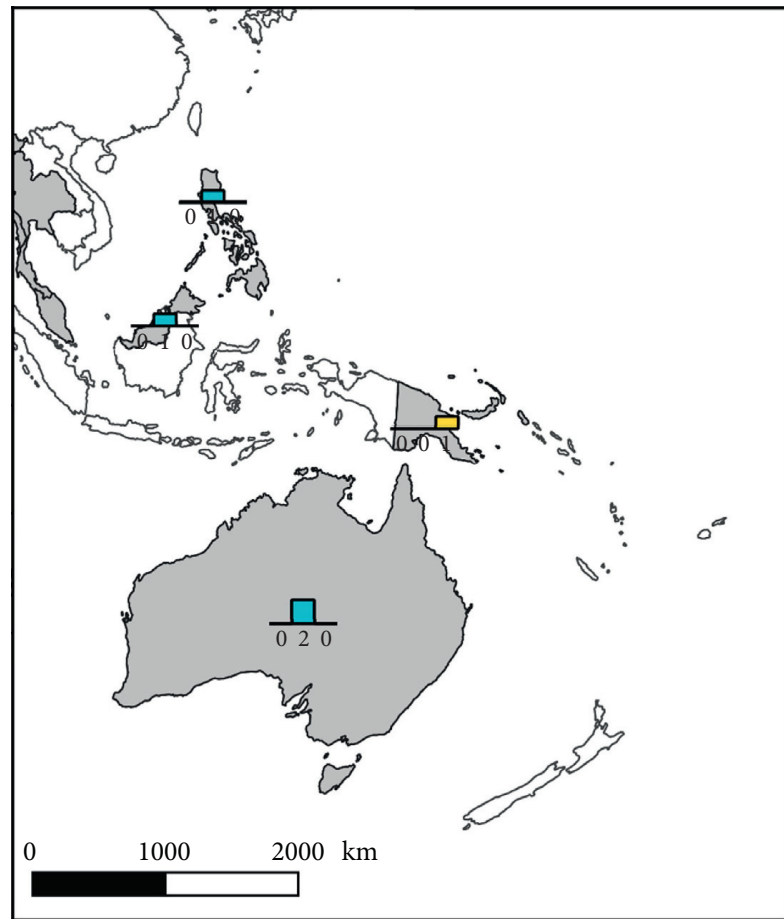

Reported countries

Scientific literature

(d)

FIGURE 2: Geographical representation of the number of reports found according to the type of publication. The maps are projected in the World Robinson coordinate reference system on QGIS 3.4.15 [76]. 
the climatic conditions. The studies analyzed were all located in countries in South Asia, and therefore, all referred to a snakebite incidence peak during the monsoon or rainy season, which reportedly lasted between 2 and 6 months (mean 3.68, 95\% CI: 3.24-4.11). The annual incidence peaks reported in the studies ranged between 33 and $84.4 \%$ of snakebite cases during the flooding times or rainy season. The mean incidence per month for these studies during the peaks was thus $16.86 \%$ (95\% CI: $15.02-18.69$ ). Based on these values and for the 28 studies, we obtained an estimated average annual incidence of $62.03 \%$ linked to flooding during the peak rainy season in South Asia.

In web media, snakebite increase was usually reported in a nonstandardized way, mostly stating that larger numbers of victims attended local hospitals or mentioning individual snakebite cases directly linked to the flooding. In addition to the events in Kerala, we found that social media have been previously used for snakebite prevention (through WhatsApp group chats) at least twice, in both South Africa and India. In these cases, social media helped to support local communities with preventive measures and to rescue both people and snakes (entries 1.69 and 1.70 in Appendix $\mathrm{S} 1$ in the supplementary material).

A recent scoping review has found a scarcity of published data on snakebite in animals in flood-prone areas [79]. One scientific article [62] and two reports in web media (entries 1.71 and 1.72 in Appendix S1 in the supplementary material) report an increase of snakebite incidence in livestock and pets in flooded areas, which would suggest that this phenomenon occurs in parallel to that in humans.

\section{Discussion}

Overall, media and some scientific reports suggest that seasonal increase of snakebite incidence in relation to flooding is caused by greater exposure of humans and snakes to each other. Such exposure may occur when floodwaters force snakes out of their burrows and home ranges, ostensibly putting them in closer contact with people (including emergency rescuers) in houses, shelters, or higher grounds (Table 1 and entries 1.1, 1.25, 1.50-1.55, 1.63, and 1.65-66 in Appendix S1 in the supplementary material). Only a handful of studies have directly examined response of snakes to monsoonal rains or floodwaters, although seasonal cycles of activity are strong and ubiquitous [80]. Responses vary by species and include shifts in encounter rate, feeding rate, reproductive rate, and body condition that precede or coincide with monsoons or hurricanes [81-86], but also the absence of obvious responses [87].

Of the articles reviewed, only five reported a negative correlation between flooding and increased snakebite incidence or no differences between seasons $[22,60,63,70,77]$. These results can be explained in different ways. In Costa Rica, Chaves et al. [70] reported both negative and positive correlations depending on the area. In India and the U.S.A., the articles $[22,60,63]$ share environmental and geographic conditions with many other papers reporting positively correlated events. Finally, the article by Moccetti et al. [77] illustrates particular environmental settings where long-term flooding is an ordinary situation (Amazon basin), and the main comparison was carried out only between the wet seasons of two years.

One factor favoring the studied phenomenon in the south Asian plains is the dynamic annual precipitation patterns, where most of the annual rain falls in a period of 3 to 4 months, leading to vast areas of land being continuously submerged under several centimeters of water. In other regions with a high risk of snakebite, such as Central and western South America, the rugged topography favors fast drainage of terrains, avoiding prolonged standing floodwaters, which challenges the common explanation of flooded burrows that force snakes to search for higher ground. To the best of our knowledge, comparable evidence from Africa about this phenomenon is not available, although snakes in Africa also exhibit increased activity during the wet season driven by activity of their prey [88].

Population density of both venomous snakes and people might also be an important factor exacerbating the different regional effects of flooding on snakebite. South of the Himalayas, densely populated (rural, semirural, and urban) areas intersect with a high abundance of venomous snakes, whereas in South and Central America, the overall population density is $2-10$ times lower, and urban areas overlap with the habitat or geographic ranges of a diverse community of medically relevant venomous snakes less often. However, Luiselli et al. [89] found no relationship between the number of venomous snake species or individuals in a part of the world and the number of snake bites that occur there.

Catastrophic events with extensive media coverage, like those in Kerala, show that the current availability of online resources is generating alternative solutions to the snakebite problem by connecting the population with networks of snake experts and snake catchers. These can give advice and, when possible, assist with the identification and relocation of dangerous snakes (entries 1.67-1.68 in Appendix S1 in the supplementary material, Jose Louies pers. comm.). The crisis management in Kerala and previous use of social media in snakebite prevention in India and South Africa are good examples of the use of online technologies to protect both people and snakes. The use of web media has become progressively accessible even to low-income populations via smartphones and the Internet. This simplified access to information might play a fundamental role in future prevention or rescue campaigns, not only as a method to contact herpetological and medical assistance, but also to disseminate preventive measures to the public.

According to global analyses, extreme weather conditions, and especially flooding, are increasing overall in frequency and magnitude [90-92]. Depending on local conditions, more intense, prolonged, and unpredictable flooding, in combination with relentlessly growing human populations and encroachment on wild environments, will likely mean higher snakebite risk and incidence $[63,70]$.

\section{Conclusions}

The relationship between flooding and the increased incidence of snakebite has been observed since the late 1800s, 
but it is usually mentioned only in passing and has rarely been quantified. Most reports associated flooding with an increased incidence of snakebite. Our review shows that flooding seems to dramatically increase the exposure of people and snakes to each other.

WhatsApp, Twitter, text messages, and other mobile communication methods as well as social media are playing an increasingly important role in prevention and management of snakebite emergencies. The International Telecommunication Union reported that about $97 \%$ of the world population lives within the reach of a mobile cellular signal, and that coverage is $88.7 \%$ in the least developed countries [93]. Innovative applications of conventional technology, such as RapidSMS, aim to improve social, environmental, and health issues of populations most in need, such as those in remote places [94], facilitating the collection and sharing of complex information via SMS. Improving access to mobile communications by the populations most affected by snakebite and flooding has started to provide valuable support for the prevention and management of this NTD, especially after flooding events.

\section{Conflicts of Interest}

The authors declare that there are no conflicts of interest regarding the publication of this paper.

\section{Acknowledgments}

The authors thank the Swiss National Science Foundation for funding the SNAKE-BYTE project (no. 315130_176271). Rafael Ruiz de Castañeda was partly funded by the LouisJeantet Foundation. Andrew M. Durso was funded by the Fondation privée des Hôpitaux Universitaires de Genève (award QS04-20).

\section{Supplementary Materials}

The supplementary material file consists of two main elements: an appendix containing the links to the web media reviewed, the grey literature analyzed, and the search patterns for three different search engines and a table summarizing the hits found mentioning the relationship between snakebite and flooding according to type of media, continent, country, and species of snake. (Supplementary Materials)

\section{References}

[1] J. M. Gutiérrez, J. J. Calvete, A. G. Habib, R. A. Harrison, D. J. Williams, and D. A. Warrell, "Snakebite envenoming," Nature Reviews Disease Primers, vol. 3, no. 1, pp. 1-21, 2017.

[2] U. Adiga and S. Adiga, "An epidemiological study on snakebite in Karwar," Journal of International Medicine and Dentistry, vol. 1, no. 2350, pp. 70-74, 2014.

[3] E. Alirol, S. K. Sharma, H. S. Bawaskar, U. Kuch, and F. Chappuis, "Snake bite in south Asia: a review," PLoS Neglected Tropical Diseases, vol. 4, no. 1, Article ID e603, 2010.

[4] A. Anjum, M. Husain, S. Hanif, S. Ali, M. Beg, and M. Sardha, "Epidemiological profile of snake bite at tertiary care hospital, north India," Journal of Forensic Research, vol. 3, no. 4, p. 201, 2012.

[5] C. Arnold, "Vipers, mambas and taipans: the escalating health crisis over snakebites," Nature, vol. 537, no. 7618, pp. 26-28, 2016.

[6] N. Aryal, M. Thapa, U. Singh, and M. Shrestha, "A descriptive epidemiological study of snake bite cases among children in Eastern Nepal," Medical Journal of Shree Birendra Hospital, vol. 16, no. 2, pp. 10-17, 2017.

[7] G. Brunda and R. Sashidhar, "Epidemiological profile of snake-bite cases from Andhra Pradesh using immunoanalytical approach," Indian Journal of Medical Research, vol. 125, no. 5, pp. 661-669, 2007.

[8] A. Calmette, "Étude expérimentale du venin de naja tripudians ou cobra capel et exposé d'une méthode de neutralisation de ce venin dans l'organisme," Annales de l'Institut Pasteur, vol. 6, no. 3, pp. 160-183, 1892.

[9] A. Chandrakumar, T. N. K. Suriyaprakash, P. L. Mohan, L. Thomas, and P. V. Vikas, "Evaluation of demographic and clinical profile of snakebite casualties presented at a tertiary care hospital in Kerala," Clinical Epidemiology and Global Health, vol. 4, no. 3, pp. 140-145, 2016.

[10] S. Chaudhary, S. Singh, N. Chaudhary, and S. Mahato, "Snake-bite in Nepal," Journal of Universal College of Medical Sciences, vol. 2, no. 3, pp. 45-53, 2014.

[11] L. S. Cruz, R. Vargas, and A. A. Lopes, "Snakebite envenomation and death in the developing world," Ethnicity \& Disease, vol. 19, no. 1, pp. S1-S42, 2009.

[12] K. Dayananda, P. J. M. Reddy, E. V. N. Raju, and T. H. Babu, "Epidemiological study of snakebite cases admitted in victoria hospital, Bangalore," International Journal of Medicine and Medical Sciences, vol. 46, no. 3, p. 1304, 2013.

[13] J. M. Farooqui, B. B. Mukherjee, S. N. M. Manjhi, A. A. J. Farooqui, and S. Datir, "Incidence of fatal snake bite in Loni, Maharashtra: an autopsy based retrospective study (2004-2014)," Journal of Forensic and Legal Medicine, vol. 39, pp. 61-64, 2016.

[14] M. Faiz and Q. T. Islam, "Climate change and health," Journal of Bangladesh College of Physicians Surgeons, vol. 28, no. 1, pp. 1-3, 2010.

[15] E. S. Feitosa, V. Sampaio, J. Sachett et al., "Snakebites as a largely neglected problem in the brazilian amazon: highlights of the epidemiological trends in the state of amazonas," Revista da Sociedade Brasileira de Medicina Tropical, vol. 48, no. 1, pp. 34-41, 2015.

[16] A. Ghose and A. Faiz, "Snake envenomation in Bangladesh," in Clinical Toxinology in Asia Pacific and Africa, pp. 233-249, Springer, Berlin, Germany, 2015.

[17] F. González-Andrade and J.-P. Chippaux, "Snake bite envenomation in Ecuador," Transactions of the Royal Society of Tropical Medicine and Hygiene, vol. 104, no. 9, pp. 588-591, 2010.

[18] B. Halesha, L. Harshavardhan, A. J. Lokesh, P. Channaveerappa, and K. Venkatesh, "A study on the clinico-epidemiological profile and the outcome of snake bite victims in a tertiary care centre in southern India," Journal of Clinical and Diagnostic Research: JCDR, vol. 7, no. 1, p. 122, 2013.

[19] A. S. Hayat, A. H. Khan, T. Z. Shaikh, R. A. Ghouri, and N. Shaikh, "Study of snake bite cases at Liaquat University hospital Hyderabad/Jamshoro," Journal of Ayub Medical College Abbottabad, vol. 20, no. 3, pp. 125-127, 2008.

[20] I. F. Inamdar, N. R. Aswar, M. Ubaidulla, and S. D. Dalvi, "Snakebite: admissions at a tertiary health care centre in 
Maharashtra, India," South African Medical Journal, vol. 100, no. 7, pp. 456-458, 2010.

[21] A. Ishfaq, "Hematotoxicity in patients with snake bite," Journal of Rawalpindi Medical College, vol. 18, no. 1, pp. 20-22, 2014.

[22] N. E. Jones and M. D. Baker, "Toxicologic exposures associated with natural disasters: gases, kerosene, ash, and bites," Clinical Pediatric Emergency Medicine, vol. 13, no. 4, pp. 317-323, 2012.

[23] H. Joshi, S. Mahmood, M. Joshi, I. Shaifali, and P. Srivastava, "Batı Nepal'de görülen yilan sokmasi vakalarinin klinik ve," TAF Preventive Medicine Bulletin, vol. 11, no. 1, pp. 57-62, 2012.

[24] V. Khan, D. Zala, M. Kakadiya, and V. Das, "Epidemiology and fatal outcomes of snakebite in the union territory of Dadra and Nagar Haveli," International Journal of Medical Science and Public Health, vol. 6, no. 7, pp. 1201-1203, 2017.

[25] D. P. Koirala, E. Gauchan, S. Basnet, S. Adhikari, and G. BK, "Clinical features, management and outcome of snake bite in children in Manipal teaching hospital," Nepal Journal of Medical Sciences, vol. 2, no. 2, pp. 119-124, 2013.

[26] V. Y. Kshirsagar, M. Ahmed, and S. M. Colaco, "Clinical profile of snake bite in children in rural India," Iranian Journal of Pediatrics, vol. 23, no. 6, p. 632, 2013.

[27] D. Majumder, A. Sinha, S. K. Bhattacharya, R. Ram, U. Dasgupta, and A. Ram, "Epidemiological profile of snake bite in south 24 Parganas district of West Bengal with focus on underreporting of snake bite deaths," Indian Journal of Public Health, vol. 58, no. 1, p. 17, 2014.

[28] M. T. Miah, A. A. Hoque, B. K. Tarafder, M. K. H. Patwary, R. R. Khan, and S. M. E. J. Kabir, "Epidemiology, clinical profile and outcome of patients of snake bite in Mymensingh Medical College Hospital," Journal of Bangladesh College of Physicians and Surgeons, vol. 27, no. 2, pp. 70-75, 2009.

[29] B. Mohapatra, D. A. Warrell, W. Suraweera et al., "Snakebite mortality in India: a nationally representative mortality survey," PLoS Neglected Tropical Diseases, vol. 5, no. 4, Article ID e1018, 2011.

[30] R. Nigam, D. Kosam, and M. D. M. Murthy, "Retrospective study of neuroparalytic snake envenomation in a tertiary care hospital of Chhattisgarh," Journal of Evolution of Medicine and Dental Sciences, vol. 4, 2015.

[31] D. P. Pandey, G. Subedi Pandey, K. Devkota, and M. Goode, "Public perceptions of snakes and snakebite management: implications for conservation and human health in southern Nepal," Journal of Ethnobiologyand Ethnomedicine, vol. 12, no. 1, p. 22, 2016.

[32] G. Paridhi and D. Nilesh, "Monsoon months: think about snake bite!" Asian Pacific Journal of Health Sciences, vol. 2, no. 2, pp. 64-66, 2015.

[33] M. Patra, S. Tripathy, and I. Jena, "Health hazards by sea cyclones in Odisha, the supercyclone and the Phailin," Odisha Review, vol. 30, 2013.

[34] V. Poudyal, K. Paudal, N. Rana, and S. Adhikari, "A hospital based study on snake bite poisoning in adults in the western region of Nepal," Journal of Chitwan Medical College, vol. 6, no. 3, pp. 33-38, 2016.

[35] P. Praveen Kumar Reddy and M. Senthilvelan, "A study of clinical profile of snake bite," International Journal of Modern Research and Reviews, vol. 3, no. 10, pp. 964-968, 2015.

[36] R. Rahman, M. A. Faiz, S. Selim et al., "Annual incidence of snake bite in rural Bangladesh," PLoS Neglected Tropical Diseases, vol. 4, no. 10, Article ID e860, 2010.
[37] C. P. Rao, P. Shivappa, and V. R. Mothi, "Fatal snake bitessociodemography, latency pattern of injuries," Journal of Occupational Medicine and Toxicology, vol. 8, no. 1, p. 7, 2013.

[38] A. S. Reza, S. N. Islam, A. Ghosh, M. R. Rahman, M. Faiz, and A. Rahim, "Magnitude of snake bite and drowing during monsoon flood in two districts of Bangladesh," Journal of Shaheed Suhrawardy Medical College, vol. 7, no. 1, pp. 3-5, 2015.

[39] R. Roshnath, E. KunhIraman, and C. V. Rajan, "Incidence of snake bite and corresponding compensation payments in the Kannur district of Kerala, India," Herpetological Bulletin, vol. 143, p. 27, 2018.

[40] G. S. Sahni, "Clinico-epidemiological profile of snake bite in children-a descriptive study," Indian Journal of Child Health, vol. 4, no. 4, pp. 503-506, 2017.

[41] N. Sharma, S. Chauhan, S. Faruqi, P. Bhat, and S. Varma, "Snake envenomation in a north Indian hospital," Emergency Medicine Journal, vol. 22, no. 2, pp. 118-120, 2005.

[42] R. Sharma, V. Dogra, G. Sharma, and V. Chauhan, "Mass awareness regarding snake bite induced early morning neuroparalysis can prevent many deaths in North India," International Journal of Critical Illness Injury Science, vol. 6, no. 3, p. 115, 2016.

[43] K. Shyna, K. Sudhakaran, and M. Mohammed, "A clinical profile of poisonous snake bite in children of North Kerala, India," International Journal of Contemporary Pediatrics, vol. 5, no. 2, pp. 310-313, 2018.

[44] A. Singh, S. Goel, A. Singh et al., "An epidemiological study of snakebites from rural Haryana," International Journal of Advanced Medical and Health Research, vol. 2, no. 1, p. 39, 2015.

[45] E. J. Wozniak, J. Wisser, and M. Schwartz, "Venomous adversaries: a reference to snake identification, field safety, and bite-victim first aid for disaster-response personnel deploying into the hurricane-prone regions of North America," Wilderness \& Environmental Medicine, vol. 17, no. 4, pp. 246-266, 2006.

[46] C. Yañez-Arenas, A. Yañez-Arenas, and D. Martínez-Ortíz, "Panorama epidemiológico de las mordeduras por serpiente venenosa en el estado de Yucatán, México (2003-2012)," Gaceta Médica de México, vol. 152, no. 4, pp. 568-574, 2016.

[47] C. M. Sant'Ana Malaque and J. M. Gutiérrez, "Snakebite envenomation in central and South America," in Critical Care Toxicology, pp. 1-22, Mosby, Maryland Heights, MI, USA, 2016.

[48] Recommendation for the Adoption of an Additional Disease as a Neglected Tropical Disease, The Case for Snakebite Envenoming, 2017.

[49] P. Wallemacq and M. Moitinho de Almeida, "Flash floods. Sharing of field experience - Kerala," PreventionWeb, vol. 53, 2018.

[50] ICRC, Humanitarian Futures for Messaging Apps, ICRC (International Committee of the Red Cross) the Engine Room and Block Party, Geneva, Switzerland, 2017.

[51] OCHA, "Hashtag standards for emergencies," Technical report, United Nations Office for the Coordination of $\mathrm{Hu}-$ manitarian Afairs, New York, NY, USA, 2014.

[52] M. T. Alam, M. A. Wadud, and M. S. U. Islam, "A study of snake bite cases in Faridpur medical college hospital, Faridpur," Faridpur Medical College Journal, vol. 9, no. 1, pp. 32-34, 2014.

[53] M. R. Amin, "Antivenom for snake bite: critical supply in health care settings," Journal of Medicine, vol. 11, no. 1, pp. 57-59, 2010. 
[54] P. Chakraborty, J. Deb Nath, M. Faiz, A. Das, and A. Q. Chowdhury, "Clinical study of snakebite cases admitted in dhaka medical college hospital," Chattagram Maa-OShishu Hospital Medical College Journal, vol. 13, no. 1, pp. 7-12, 2014.

[55] J. M. Gutiérrez, "Snakebite envenoming in Latin America and the caribbean," in Clinical Toxinology in Australia, Europe, and Americas, C.-W. Vogel, S. A. Seifert, D. V. Tambourgi, and S. N. Toxinology, Eds., pp. 51-72, Springer, Berlin, Germany, 2018.

[56] R. Krishnappa, R. Gowda, P. Babu, and R. Banala, “A study on demographical and clinical profile and the outcome of snake bite victims in a tristate tertiary care center," International Journal of Medical Science and Public Health, vol. 5, no. 9, pp. 1818-1823, 2016.

[57] S. Laohawiriyakamol, S. Sangkhathat, P. Chiengkriwate, and S. Patrapinyokul, "Surgery in management of snake envenomation in children," World Journal of Pediatrics, vol. 7, no. 4, pp. 361-364, 2011.

[58] C. Vasavi and P. M. Rao, "Epidemiological study of snake bite cases in government general hospital, guntur," International Journal of Advances in Health Sciences, vol. 2, no. 4, pp. 444-447, 2015.

[59] S. Rana, C. Nanda, R. Singh, and S. Kumar, "Management of snake bite in India-revisited," JK Science, vol. 17, no. 1, 2015.

[60] P. S. Pius, J. Vinoj, I. Indhuja, P. Premkumar, and A. Diwakaran, "A retrospective review of snake bite cases admitted in a tertiary care hospital," Journal of Evidence Based Medicine and Healthcare, vol. 3, no. 67, pp. 3636-3639, 2016.

[61] E. Siddique, P. Bhat, S. Kulkarni, V. Trasad, and S. Thakur, "Public awareness, knowledge, attitude and acceptance of dental implants as a treatment modality among patients visiting SDM college of dental sciences and hospital, Dharwad," Archives of Pharmacy Practice, vol. 6, no. 3, pp. 58-63, 2015.

[62] N. Sastry, "Managing livestock sector during floods and cyclones," Journal of Rural Development, vol. 13, no. 4, pp. 583-592, 1994.

[63] R. Cox, T. Amundson, and B. Brackin, "Evaluation of the patterns of potentially toxic exposures in Mississippi following hurricane Katrina," Clinical Toxicology, vol. 46, no. 8, pp. 722-727, 2008.

[64] M. L. Fernández, E. A. de Belaustegui, and R. E. Servín, "Mordedura de yarará en pacientes pediátricos," Revista de la Facultad de Medicina, vol. 29, no. 1, pp. 10-15, 2009.

[65] J. K. Tucker, "Notes on road-killed snakes and their implications on habitat modification due to summer flooding on the Mississippi River in west central Illinois," Transactions of the Illinois State Academy of Science, vol. 88, no. 1/2, pp. 61-71, 1995.

[66] M. Kaushik, V. Banyal, S. Sondhi, M. K. Thakur, and A. Kaushik, "Clinical profile of snake bite patients in tertiary care hospital in Himachal Pradesh: a prospective study," International Journal of Research in Medical Sciences, vol. 6, no. 7, p. 2444, 2018.

[67] R. d. S. Leite, I. T. G. Targino, Y. A. C. F. Lopes, R. M. Barros, and A. A. Vieira, "Epidemiology of snakebite accidents in the municipalities of the state of Paraíba, Brazil," Ciência \& Saúde Coletiva, vol. 18, no. 5, pp. 1463-1471, 2013.

[68] M. Sasa and S. Vazquez, "Snakebite envenomation in Costa Rica: a revision of incidence in the decade 1990-2000," Toxicon, vol. 41, no. 1, pp. 19-22, 2003.

[69] J. Boadas, M. Matos, S. Bónoli et al., "Perfil eco-epidemiológico de los accidentes por ofidios en Monagas,
Venezuela (2002-2006," Boletín de Malariologia y Salud Ambiental, Universidad Central de Venezuela, Caracas, Venezuela, 2012.

[70] L. F. Chaves, T.-W. Chuang, M. Sasa, and J. M. Gutiérrez, "Snakebites are associated with poverty, weather fluctuations, and El Niño," Science Advances, vol. 1, no. 8, Article ID e1500249, 2015.

[71] J.-P. Chippaux, V. Rage-Andrieux, V. Le Mener-Delore, M. Charrondiere, P. Sagot, and J. Lang, "Epidemiologie des envenimations ophidiennes dans le nord du cameroun," Bulletin de la Société de Pathologie Exotique, vol. 95, no. 3, pp. 184-187, 2002.

[72] D. S. Ediriweera, P. J. Diggle, A. Kasturiratne et al., "Evaluating temporal patterns of snakebite in Sri Lanka: the potential for higher snakebite burdens with climate change," International Journal of Epidemiology, vol. 47, no. 6, pp. 2049-2058, 2018.

[73] A. M. Kularatne, A. Silva, K. Maduwage et al., "Victims' response to snakebite and socio-epidemiological factors of 1018 snakebites in a tertiary care hospital in Sri Lanka," Wilderness \& Environmental Medicine, vol. 25, no. 1, pp. 35-40, 2014.

[74] D. P. Pandey, "Epidemiology of snakebites based on field survey in Chitwan and Nawalparasi districts, Nepal," Journal of Medical Toxicology, vol. 3, no. 4, pp. 164-168, 2007.

[75] M. Shubhankar and T. Ramkumar, "Effect of 'cyclone Phailin'on pediatric age group of South Odisha," International Journal of Recent Scientific Research, vol. 5, no. 10, pp. 1933-1935, 2010.

[76] QGIS Geographic Information System. 3.4.9, QGIS Development Team, 2019.

[77] N. N. Moccetti, C. F. Caldas, and D. R. Delgado, "Impacto de las inundaciones sobre la casuística de enfermedades zoonóticas y accidentes producidos por mordedura de animales registrada en un hospital general de la ciudad de Iquitos, Loreto, Perú," Theorēma, vol. 2, pp. 11-17, 2015.

[78] S. G. Hansdak, K. S. Lallar, P. Pokharel, P. Shyangwa, P. Karki, and S. Koirala, "A clinico-epidemiological study of snake bite in Nepal," Tropical Doctor, vol. 28, no. 4, pp. 223-226, 1998.

[79] I. Bolon, M. Finat, M. Herrera et al., "Snakebite in domestic animals: first global scoping review," Preventive Veterinary Medicine, vol. 170, p. 104729, 2019.

[80] E. A. Eskew and B. D. Todd, "Too cold, too wet, too bright, or just right? Environmental predictors of snake movement and activity," Copeia, vol. 105, no. 3, pp. 584-591, 2017.

[81] F. S. Bernardino Jr., and G. H. Dalrymple, "Seasonal activity and road mortality of the snakes of the pa-hay-okee wetlands of Everglades National Park, USA," Biological Conservation, vol. 62, no. 2, pp. 71-75, 1992.

[82] P. G. May, T. M. Farrell, S. T. Heulett et al., "Seasonal abundance and activity of a rattlesnake (Sistrurus miliarius barbouri) in central Florida," Copeia, vol. 1996, no. 2, pp. 389-401, 1996.

[83] G. P. Brown, R. Shine, and T. Madsen, "Responses of three sympatric snake species to tropical seasonality in northern Australia," Journal of Tropical Ecology, vol. 18, no. 4, pp. 549-568, 2002.

[84] Y.-L. Liu, H. B. Lillywhite, and M.-C. Tu, "Sea snakes anticipate tropical cyclone," Marine Biology, vol. 157, no. 11, pp. 2369-2373, 2010.

[85] S. C. Rahman, S. Rashid, K. Das, C. Jenkins, and L. Luiselli, "Monsoon does matter: annual activity patterns in a snake assemblage from Bangladesh," The Herpetological Journal, vol. 23, no. 4, pp. 203-208, 2013. 
[86] J. L. Rheubert, L. Freeborn, D. M. Sever, D. S. Siegel, and K. M. Gribbins, "Agkistrodon piscivorus spermatogenesis addendum: the effect of Hurricane Katrina on spermatogenesis of the western cottonmouth snake," Spermatogenesis, vol. 4, no. 3, Article ID e988586, 2014.

[87] G. L. Carfagno and P. J. Weatherhead, "Ratsnake response to bottomland flooding: implications for avian nest predation," Acta Herpetologica, vol. 4, no. 2, pp. 191-194, 2009.

[88] L. Luiselli, "Interspecific relationships between two species of sympatric afrotropical water snake in relation to a seasonally fluctuating food resource," Journal of Tropical Ecology, vol. 22, no. 1, pp. 91-100, 2006.

[89] L. Luiselli, L. Sale, G. C. Akani, and G. Amori, "Venomous snake abundance within snake species' assemblages worldwide," Diversity, vol. 12, no. 2, p. 69, 2020.

[90] W. R. Berghuijs, E. E. Aalbers, J. R. Larsen, R. Trancoso, and R. A. Woods, "Recent changes in extreme floods across multiple continents," Environmental Research Letters, vol. 12, no. 11, Article ID 114035, 2017.

[91] M. Wahlstrom and D. Guha-Sapir, The Human Cost of Weather-Related Disasters 1995-2015, UNISDR, Geneva, Switzerland, 2015.

[92] J. A. Vano, K. Miller, M. D. Dettinger et al., "Hydroclimatic extremes as challenges for the water management community: lessons from oroville dam and hurricane harvey," Bulletin of the American Meteorological Society, vol. 100, no. 1, pp. S9S14, 2019.

[93] ITU, Measuring Digital Development: Facts and Figures, International Telecommunication Union, Geneva, Switzerland, 2019.

[94] Caktus, "RapidSMS," 2020, https://www.rapidsms.org/.17/ Feb/2020. 